OPEN ACCESS

Edited by:

Marilia Seelaender,

University of São Paulo, Brazil

Reviewed by:

Takahiko Shimizu,

National Center for Geriatrics and Gerontology (NCGG), Japan

Jennifer Stevenson Moylan, University of Kentucky, United States

*Correspondence: Vera C. Mazurak vmazurak@ualberta.ca

Specialty section: This article was submitted to Striated Muscle Physiology, a section of the journal Frontiers in Physiology

Received: 17 March 2021 Accepted: 30 April 2021

Published: 03 June 2021

Citation:

Isesele PO and Mazurak VC (2021) Regulation of Skeletal Muscle Satellite Cell Differentiation by Omega-3

Polyunsaturated Fatty Acids: A Critical Review.

Front. Physiol. 12:682091. doi: 10.3389/fphys.2021.682091

\section{Regulation of Skeletal Muscle Satellite Cell Differentiation by Omega-3 Polyunsaturated Fatty Acids: A Critical Review}

\author{
Peter O. Isesele and Vera C. Mazurak* \\ Division of Human Nutrition, Faculty of Agricultural, Life and Environmental Sciences, University of Alberta, Edmonton, AB, \\ Canada
}

Skeletal muscle is composed of multinuclear cells called myofibres, which are formed by the fusion of myoblasts during development. The size of the muscle fiber and mass of skeletal muscle are altered in response to several pathological and physiological conditions. Skeletal muscle regeneration is primarily mediated by muscle stem cells called satellite cells (SCs). In response to injury, these SCs replenish myogenic progenitor cells to form new myofibers to repair damaged muscle. During myogenesis, activated SCs proliferate and differentiate to myoblast and then fuse with one another to form muscle fibers. A reduced number of SCs and an inability to undergo myogenesis may contribute to skeletal muscle disorders such as atrophy, cachexia, and sarcopenia. Myogenic regulatory factors (MRF) are transcription factors that regulate myogenesis and determines whether SCs will be in the quiescent, activated, committed, or differentiated state. Mitochondria oxidative phosphorylation and oxidative stress play a role in the determination of the fate of SCs. The potential activation and function of SCs are also affected by inflammation during skeletal muscle regeneration. Omega-3 polyunsaturated fatty acids (PUFAs) show promise to reduce inflammation, maintain muscle mass during aging, and increase the functional capacity of the muscle. The aim of this critical review is to highlight the role of omega-3 PUFAs on the myogenic differentiation of SCs and pathways affected during the differentiation process, including mitochondrial function and inflammation from the current body of literature.

Keywords: inflammation, myogenesis, omega-3, satellite cell, skeletal muscle

\section{INTRODUCTION}

Skeletal muscle occupies about $40 \%$ of total body weight and is a highly dynamic tissue (Frontera and Ochala, 2015). Skeletal muscle accounts for 30-50\% of whole-body protein turnover and stores and utilizes substrates, including amino acids and carbohydrates (Frontera and Ochala, 2015). Skeletal muscle is composed of multinuclear cells called myofibers (Fukada, 2018), which are formed by the fusion of myoblasts during development (Yin et al., 2013). The size of the muscle fiber and skeletal muscle mass are altered in different pathological and 
physiological conditions (Schiaffino et al., 2013). When the muscle is injured, it responds by activating a complex response leading to repair and regeneration of the injured tissue (Tidball, 2011; Barthélémy et al., 2018; Morgan and Partridge, 2020). Skeletal muscle regeneration is primarily mediated by satellite cells (SCs; Lepper et al., 2011; Yamamoto et al., 2018), which replenish myogenic progenitor cells and differentiate into new myofiber for muscle repair in response to injury (Relaix and Marcelle, 2009; McCarthy et al., 2011; Fukada, 2018). SCs are positioned to receive signals from the surrounding environment (Dumont et al., 2015; Fukada, 2018). SCs represent between 2 and $10 \%$ of total myonuclei per muscle fiber, and they have self-renewal ability and capacity to give rise to functional progeny. A reduction of SC number and/or an inability to undergo myogenesis may contribute to skeletal muscle disorders such as atrophy and sarcopenia (McKenna and Fry, 2017).

Like stem cells found in other tissues, SCs in an undamaged adult muscle are maintained in a quiescent and undifferentiated state (Montarras et al., 2013). Myogenic regulatory factors (MRF) are transcription factors that regulate myogenesis and determine whether SCs will be in the quiescent, activated, committed, or differentiated state (Olguin and Olwin, 2004; Hernández-Hernández et al., 2017; Zammit, 2017). Transcription factors from the Paired box gene family, Pax3 and Pax7, are critical for satellite cell biogenesis, survival, and potentially self-renewal (Collins et al., 2009). Myoblast determination protein $1(M y o D)$ is the master gene for myogenesis, is expressed at an early stage of myogenic differentiation, and induces the expression of other myogenesis-related genes such as myogenin (MyoG) and MRF4 (Kassar-Duchossoy et al., 2004; Przewoźniak et al., 2013). MyoD interacts with several metabolic genes involved in mitochondria biogenesis, fatty acid oxidation, and electron transport chain function. The process of myogenic differentiation is illustrated in Figure 1. Quiescent SCs have a minimal number of mitochondria, assessed by reduced levels of mitochondria DNA (mtDNA) tightly packed around the nucleus (Latil et al., 2012). Activated SCs, compared to quiescent SC, rely more on the mitochondria to produce ATP through $\beta$-oxidation and oxidative phosphorylation (Ryall et al., 2015). In addition to the role of the mitochondria, inflammation also plays a role in skeletal muscle regeneration (Perandini et al., 2018; Yang and $\mathrm{Hu}, 2018$ ). The transcription factor, nuclear factor-kappa B (NF- $\mathrm{B})$, activated by tumor necrosis factor (TNF- $\alpha$ ), induces signals that attracts muscle stem cells to the damaged site and promotes proliferation of SCs (Peterson et al., 2011). Myogenesis is also regulated by interleukin (IL)-6 dependent activation of signal transducer and activator of transcription (STAT3; Serrano et al., 2008).

The proliferation and differentiation of SCs can be modulated by nutrients such as dietary carbohydrate, vitamin D, and Vitamin E (Chapalamadugu et al., 2009; Alami-Durante et al., 2011; Khor et al., 2016; Braga et al., 2017); however, their effect varies depending on the origin of muscle type (Powell et al., 2014). Omega-3 polyunsaturated fatty acids (PUFAs) have been shown to increase the functional capacity of the muscle and enable maintenance of muscle mass in aging and chronic disease (reviewed by McGlory et al., 2019; Lam et al., 2020). Omega-3 PUFAs have the potential to regulate the complex process of skeletal muscle regeneration and differentiation due to their ability to regulate gene expression (Price et al., 2000), mitochondria biogenesis (Katyare and Mali, 2016), and inflammation (Calder, 2010). Dietary omega-3 PUFAs, eicosapentaenoic acid (EPA; 20:5n-3),

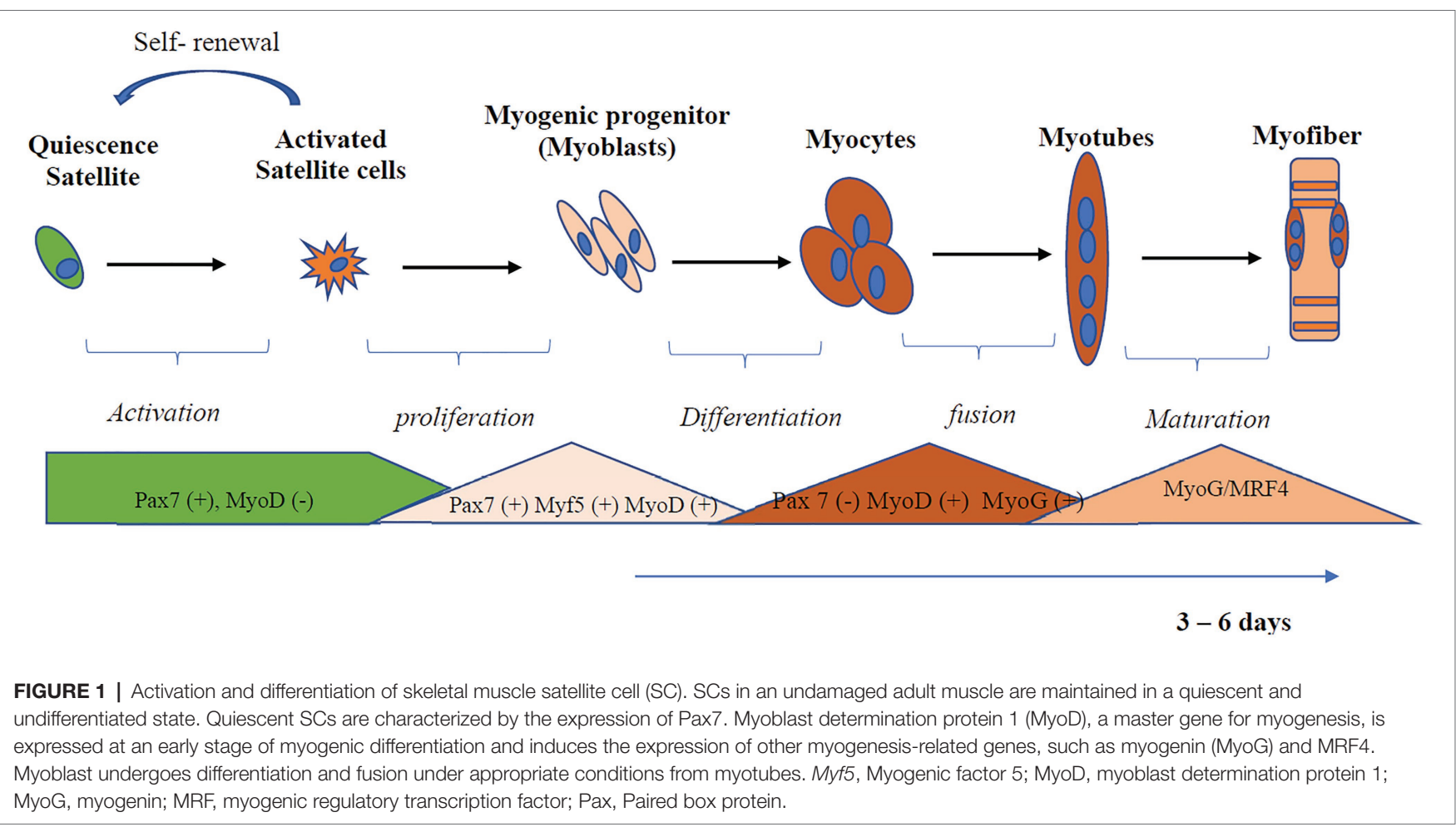


and docosahexaenoic acid (DHA; 22:6n-3) have been shown to be involved in the myogenic program of SCs (reviewed by Bhullar et al., 2016) and skeletal muscle regeneration (reviewed by Tachtsis et al., 2018). However, little is known about how omega-3 PUFA regulates mitochondrial function and inflammation during myogenic differentiation. A recent review (Bhattacharya and Scime, 2020) highlights how mitochondrial function and dynamics affect oxidative phosphorylation and the production of reactive oxygen species to directly impact SC differentiation. The aim of the present review is to consolidate studies that have applied omega-3 PUFA under experimental conditions to study myogenic differentiation that have been published since the review by Bhullar et al. (2016). Since that time, the emerging literature has focused on transcriptional factors regulating myogenesis; this review will evaluate studies exploring the effect of omega-3 PUFAs on the transcriptional regulation of myogenesis.

\section{SEARCH METHOD}

A comprehensive literature search was carried out using PUBMED MEDLINE database. The search included studies published between January 2015 and January 2021. The following keywords were used for literature search: omega-3 PUFAs, eicosapentaenoic acid (EPA), docosahexaenoic acid (DHA), satellite cell, skeletal muscle stem cell, stem cell, AND skeletal muscle, and myogenesis. The search was limited to articles written in English and with full text available. Research articles were screened by title and abstract, and a hand search of reference lists of review articles was performed for relevant studies before they were excluded. Studies were included and considered relevant if they were original articles with omega-3 PUFA intervention and a measure of myogenic differentiation-associated parameters (myogenesis, mitochondria function, or inflammation). Studies were excluded if skeletal muscle cells were not used and if they focused only on protein metabolism, insulin resistance, lipidomic profile, or other pathways unrelated to myogenesis. The information extracted from each study includes model type used, differentiation media, duration of differentiation, treatment (dose), treatment duration, myogenic parameters (myogenesis, mitochondria function, and inflammation), and findings (Table 1). The search strategy is shown in Figure 2.

\section{EXPERIMENTAL MODELS USED TO EXPLORE THE ROLE OF OMEGA-3 PUFA ON MYOGENIC DIFFERENTIATION}

The majority of studies (11 out of 13) used the $\mathrm{C} 2 \mathrm{C} 12$ cell model. The $\mathrm{C} 2 \mathrm{C} 12$ model is the most widely used model to understand molecular mechanisms of muscle differentiation and myogenesis (Cornelison, 2008). Initially, proliferating myoblasts differentiate into elongated myocytes that migrate, adhere, and fuse to one another to form small nascent myotubes (early differentiation) that contain few myonuclei. Nascent myotubes further fuse with additional myocytes or with other myotubes (terminal differentiation/maturation) to generate mature myotubes that contain many myonuclei, which then align with one another into myofibers (Abmayr and Pavlath, 2012). This mimics the process of human muscle satellite cell activation and differentiation in response to muscle injury (Almeida et al., 2016). Loss of Pax7 expression and an increase in MyoG expression characterizes a committed myoblast (Seale et al., 2000; Olguin and Olwin, 2004). The biological and molecular processes of SC activation, proliferation, differentiation, and cell fusion underline the process of skeletal muscle regeneration (Zammit, 2017). Myogenic differentiation media are frequently used to differentiate myoblasts. EPA and/or DHA is added to the media at any point along the differentiation process. Studies that differentiate myoblasts for 3-6 days and subsequently treat myotubes with EPA and/or DHA for 24 or $48 \mathrm{~h}$ aim to understand terminal maturation and fusion of the myotube. Most study designs include treatment of skeletal muscle cells with both EPA and DHA and few studies treated with EPA or DHA alone (Saini et al., 2017; Løvsletten et al., 2018; Kim et al., 2019; Lacham-Kaplan et al., 2020).

Under normal conditions, proliferation and differentiation of SCs occur in response to injury and inflammation. However, in most of the studies reviewed, differentiation was induced by a differentiation agent in the absence of injury-related conditions. The control condition applied in most of these studies is cells receiving only differentiation media, which has a much different nutrient composition than human serum. When specific fatty acids are added to the media, this provides additional substrates and nutrients that are not accounted for when the control group has no added fatty acids, posing a limitation in the interpretation of the findings. The mere presence of fatty acids per se in the treatment group could evoke responses and add an additional confounding factor to the experimental design. No studies used a control group with added fatty acids of any kind. Aligning the concentrations of serum components to physiological conditions would enhance the translatability of the studies to humans. The concentrations used in the studies ranged from 25 to $100 \mu \mathrm{M}$ of single or combined fatty acids, which aligns with the concentration of total plasma EPA and DHA in healthy young Canadians; 40 and $88.88 \mu \mathrm{M}$ of EPA and DHA, respectively (Abdelmagid et al., 2015). Most studies did not report the level of incorporation of fatty acids during differentiation (Table 1).

\section{EFFECTS OF OMEGA-3 PUFA ON MYOGENIC DIFFERENTIATION}

\section{Differentiation of $\mathrm{C2C} 12$ Myoblasts and Treatment With EPA and DHA}

Quiescent SCs are characterized by the expression of Pax7 (Seale et al., 2000). One study reported suppression of Pax7 expression by EPA+DHA treatment compared to control (Hsueh et al., 2018), suggesting that EPA+DHA induces a transition from quiescent to activated SCs. Hsueh et al. (2018) investigated the effect of $\mathrm{EPA}+\mathrm{DHA}$ on the relative expression of genes regulating terminal differentiation of myoblast into mature multinucleated myotubes. Downregulation of expression of MRF4, $M y o G$, and $M y o D$ mRNA was associated with fewer myotubes 


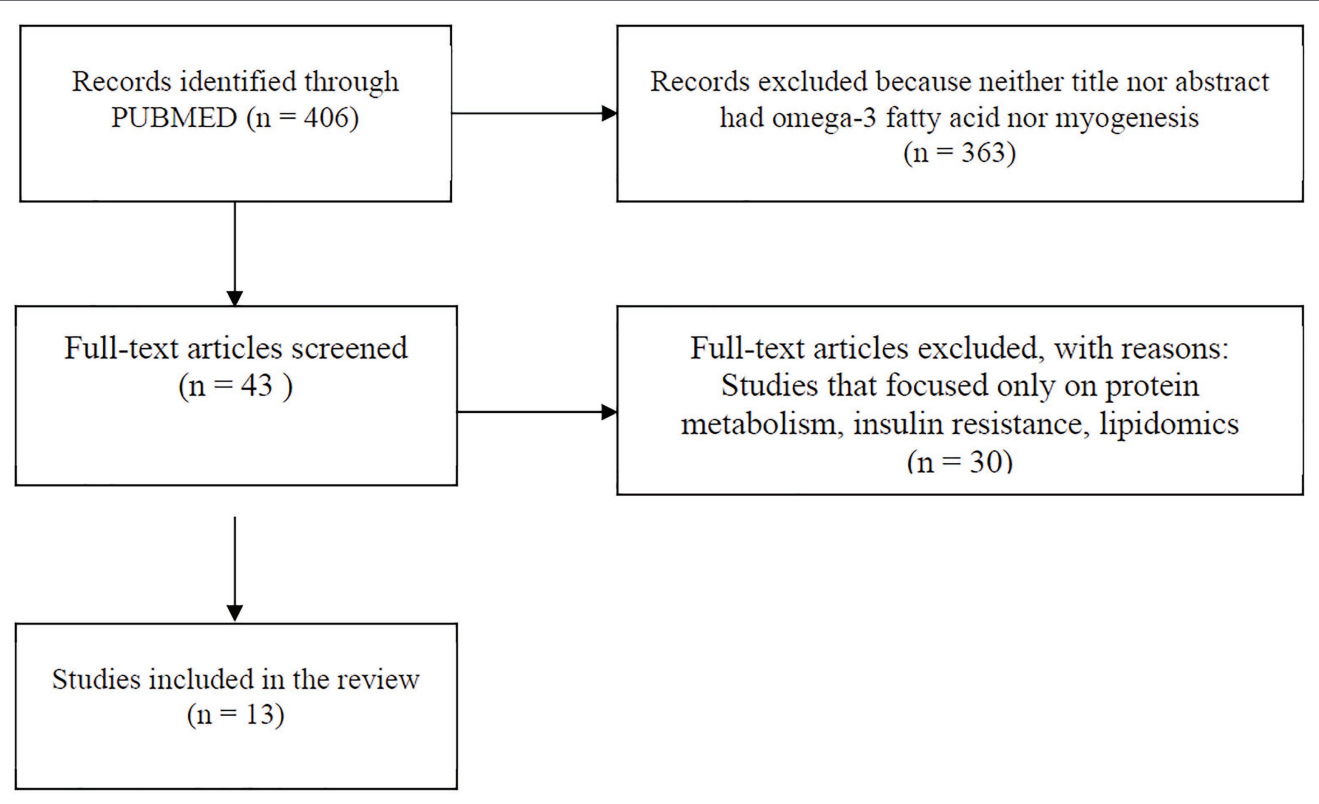

FIGURE 2 | Flowchart showing search method. Papers included were those published between January 2015 and January 2021.

with a smaller diameter in cells cultured with EPA + DHA compared to control (Hsueh et al., 2018). Myoblast proliferation and gene/protein expression of $M y o G$ were reduced at both 48 and $72 \mathrm{~h}$ with EPA and DHA treatment (Zhang et al., 2019). In a similar study, using EPA only at the same concentration $(50 \mu \mathrm{M})$ for $48 \mathrm{~h}$ resulted in significantly fewer myotubes, lower fusion index, and reduced expression of $M y o D, M y o G$, and Tmem $8 c$ (myoblast fusion related gene) compared to the control vehicle (Lacham-Kaplan et al., 2020). However, increased expression of Myf6 (Mrf4) and Myf5 was observed. Tmem $8 c$ is essential for membrane fusion and myotube extension (Gamage et al., 2017). This suggests that the treated cells were committed to the myogenic lineage; however, the cells had limited ability to fuse to form tubes as EPA suppressed expression of Tmem $8 c$. The addition of EPA to the media during the differentiation process $(72 \mathrm{~h})$ resulted in higher gene expression of $M y o D$, but no change in $M y o G$ compared to the control (Saini et al., 2017).

\section{Differentiation of Bovine-Derived Myoblast and Concurrent Treatment With DHA}

There is only one study that investigated bovine muscle cell differentiation under the influence of DHA alone ( $\mathrm{Xu}$ et al., 2018). Muscle-derived SCs were isolated from the hind muscle tissues of newborn Chinese Simmental calves, and the differentiating or proliferating myotube was incubated for 2 days with $50 \mathrm{mM}$ DHA (Xu et al., 2018). Longer multinucleated myotubes were formed, and there was a higher myotube fusion rate with DHA treatment compared to control. Similarly, the treatment of the cells with DHA in differentiation media for $48 \mathrm{~h}$ increased the expression levels of $M y o G$ and $M y h 3$ compared to the control. However, DHA treatment did not have an effect on the proliferation of the bovine skeletal muscle-derived stem cells (Xu et al., 2018). Therefore, the limited evidence suggests that DHA plays in role in regulating differentiation rather than the proliferation of SCs.

\section{Treatment of Early Differentiated Myotubes With EPA and DHA}

Shin et al. (2017) differentiated C2C12 myoblast for 4 days and then induced muscle atrophy by treatment with dexamethasone as the injury-inducing agent (Shin et al., 2017). After the addition of $25 \mu \mathrm{M}$ DHA, the atrophied myotubes recovered to having the basal levels of $M y o D$ and nucleus number, thereby rescuing the myogenic process. This suggests that the anti-atrophic effect of DHA could be due to the restoration of myogenesis by increasing $M y o D$ expression.

Overall, the effects of EPA and DHA on the formation of myotube and transcriptional regulation of myogenic differentiation are inconsistent (Figure 3). Three out of the six studies reported a decrease in myotube formation and expression of genes involved in myogenic differentiation $(M y f 5, M y o D, M y o G$, and MRF4; Hsueh et al., 2018; Zhang et al., 2019; Lacham-Kaplan et al., 2020). On the contrary, three studies (Saini et al., 2017; Shin et al., 2017; Xu et al., 2018) reported an increase in myotube formation and expression of genes involved in myogenic differentiation with EPA or DHA treatment. The reason for the discrepancies in results is not clearly understood. However, Shin et al. (2017) and $\mathrm{Xu}$ et al. (2018) reported increased myogenic differentiation by applying a concentration of $25 \mu \mathrm{M}$ and $50 \mathrm{mM}$ $\mathrm{DHA}$, respectively. In contrast, $50 \mu \mathrm{M}$ of EPA is generally used in the studies that reported decreased myogenic differentiation with EPA and DHA treatment. One other source of variation in the results obtained by these studies could be the duration of treatment of the $\mathrm{C} 2 \mathrm{C} 12$ cells with EPA or DHA. In some studies, the EPA and DHA were added to the differentiation media and present through the period of differentiation days 
TABLE 1 | Summary of studies that investigated the effects of EPA and DHA on myogenic differentiation.

\begin{tabular}{|c|c|c|c|c|c|c|c|}
\hline Reference & $\begin{array}{l}\text { Differentiation } \\
\text { period }\end{array}$ & Treatment (dose) & $\begin{array}{l}\text { Treatment } \\
\text { (duration) }\end{array}$ & Myogenesis & $\begin{array}{l}\text { Mitochondria } \\
\text { function }\end{array}$ & Inflammation & Findings \\
\hline \multicolumn{8}{|l|}{ C2C12 cells } \\
\hline Chen et al., 2016 & 6 days & $\begin{array}{l}750 \mu \mathrm{M} \text { PA or } \\
50 \mu \mathrm{M} \text { EPA and } \\
\text { DHA, AA }\end{array}$ & $24 \mathrm{~h}$ & NM & NM & $\begin{array}{l}\text { IL-6 and TNF- } \alpha \text {, } \\
\text { NF-kB, AP-1, } \\
\text { mRNA }\end{array}$ & $\begin{array}{l}\downarrow \text { PA-induced } \\
\text { proinflammatory } \\
\text { cytokine expression } \\
\text { and NF- } \mathrm{B} \text { } \\
\text { activation }\end{array}$ \\
\hline $\begin{array}{l}\text { Jeromson et al., } \\
2018\end{array}$ & $72 \mathrm{~h}$ & $\begin{array}{l}50-\mu \mathrm{M} \text { EPA and } \\
50-\mu \mathrm{M} \text { DHA }\end{array}$ & $48 \mathrm{~h}$ & NM & $\begin{array}{l}\text { OCR, function } \\
\text { [UCQR2 (complex } \\
\text { V and complex III)] }\end{array}$ & NM & $\leftrightarrow$ OCR, UCQR2 \\
\hline Hsueh et al., 2018 & 3 days & $\begin{array}{l}50 \mu \mathrm{M} \text { EPA and } \\
50-\mu \mathrm{M} \text { DHA }\end{array}$ & $\begin{array}{l}\text { Fatty acids added } \\
\text { to the } \\
\text { differentiation } \\
\text { media }\end{array}$ & $\begin{array}{l}\text { Myotube number, } \\
\text { diameter, } \\
\text { Gene expressions } \\
\text { (MRF4, MyoD, and } \\
\text { MyoG, Pax7) }\end{array}$ & $\begin{array}{l}\text { OCR, Gene } \\
\text { expression (ERR } \alpha \text {, } \\
\text { Tfam, and Pgc-1 } \alpha \text {, } \\
\text { Mitofusin2), } \\
\text { mtDNA: nDNA }\end{array}$ & NM & $\begin{array}{l}\downarrow \text { Myotubes } \\
\text { diameter, MRF4, } \\
\text { MyoD, and MyoG, } \\
\text { and Pax7 was } \\
\text { tended to } \\
\text { be suppressed } \\
\downarrow \text { mtDNA: nDNA, } \\
\text { Tfam, Pgc- } 1 \alpha, \text { OCR }\end{array}$ \\
\hline $\begin{array}{l}\text { Lacham-Kaplan } \\
\text { et al., } 2020\end{array}$ & $48-120 \mathrm{~h}$ & $50 \mu \mathrm{M}$ EPA & $\begin{array}{l}\text { Fatty acids added } \\
\text { to the } \\
\text { differentiation } \\
\text { media }\end{array}$ & $\begin{array}{l}\text { Myotube fusion } \\
\text { index, gene } \\
\text { expression } \\
\text { (MyoD1, MyoG, } \\
\text { Myh1, Tmem8c) }\end{array}$ & NM & NM & $\begin{array}{l}\downarrow \text { Lowest fusion } \\
\text { index } \\
\downarrow M y o D 1, \text { MyoG, } \\
\text { Myh1, Tmem8c }\end{array}$ \\
\hline Kim et al., 2019 & 7 days & $50-\mu \mathrm{M}$ EPA & $18 \mathrm{~h}$ & NM & $\begin{array}{l}\text { OCR, basal } \\
\text { respiration, proton } \\
\text { leak }\end{array}$ & NM & $\begin{array}{l}\downarrow \text { OCR, basal } \\
\text { respiration, proton } \\
\text { leak }\end{array}$ \\
\hline Lee et al., 2016 & 5 days & $\begin{array}{l}50 \mu \mathrm{M} \text { EPA or } \\
\mathrm{DHA}\end{array}$ & $24 \mathrm{~h}$ & NM & $\begin{array}{l}\text { mRNA levels of } \\
\text { Pgc-1 } \alpha, \text { NRF1, d } \\
\text { mtDNA copy } \\
\text { number }\end{array}$ & NM & $\begin{array}{l}\uparrow \text { mtDNA copy } \\
\text { number, Pgc-1 } 1 \alpha \text {, } \\
\text { NRF1, and Tfam }\end{array}$ \\
\hline Pinel et al., 2016 & 5 days & $\begin{array}{l}500 \mu \mathrm{M} \mathrm{PAL}+ \\
50 \mu \mathrm{M} \text { EPA }\end{array}$ & $16 \mathrm{~h}$ & NM & $\begin{array}{l}\text { Gene expression } \\
(\mathrm{Cpt} 1 \alpha, \operatorname{pgc} 1 \alpha)\end{array}$ & NM & $\uparrow C p t 1 \alpha, \leftrightarrow P g c 1 \alpha$ \\
\hline Saini et al., 2017 & 36 and $72 \mathrm{~h}$ & $50 \mu \mathrm{M}$ EPA & $\begin{array}{l}\text { Fatty acids added } \\
\text { to the } \\
\text { differentiation } \\
\text { media }\end{array}$ & $\begin{array}{l}\text { Myotube } \\
\text { formation, gene } \\
\text { expression (MyoD, } \\
\text { MyoG) }\end{array}$ & NM & NM & $\uparrow M y o D, \leftrightarrow M y o G$ \\
\hline Shin et al., 2017 & 4 days & $\begin{array}{l}25 \mu \mathrm{M} \text { or } 50 \mu \mathrm{M} \\
\mathrm{DHA}\end{array}$ & $24 \mathrm{~h}$ & $\begin{array}{l}\text { Myotube size and } \\
\text { protein expression } \\
\text { (MyoD) }\end{array}$ & NM & NM & $\begin{array}{l}\text { Recovered to have } \\
\text { the basal levels of } \\
\text { MyoD }\end{array}$ \\
\hline Young et al., 2021 & 4 days & $\begin{array}{l}100 \mu \mathrm{M} E P A, \text { and } \\
\text { DHA }\end{array}$ & $48 \mathrm{~h}$ & NM & OCR & NM & $\downarrow$ OCR \\
\hline \multicolumn{8}{|l|}{ Human Myoblast } \\
\hline $\begin{array}{l}\text { Løvsletten et al., } \\
2018\end{array}$ & 6-7 days & $100 \mu \mathrm{M}$ EPA & $24 \mathrm{~h}$ & NM & OCR, proton leak & NM & $\uparrow$ OCR, proton leak \\
\hline \multicolumn{8}{|l|}{ Bovine (MDSCs) } \\
\hline Xu et al., 2018 & $48 \mathrm{~h}$ of treatment & 50 mM DHA & $\begin{array}{l}\text { Fatty acids added } \\
\text { to the } \\
\text { differentiation } \\
\text { media }\end{array}$ & $\begin{array}{l}\text { Myotube fusion } \\
\text { rate, protein } \\
\text { expression (MyoG, } \\
\text { MyH3) }\end{array}$ & NM & NM & $\begin{array}{l}\uparrow \text { Myotube fusion } \\
\text { rate, } \uparrow \text { myotube } \\
\text { length, MyoG, and } \\
\text { MYH3 }\end{array}$ \\
\hline
\end{tabular}

All studies that used C2C12 cells were cultured in DMEM + 2\% horse serum, except Shin et al. (2017), Løvsletten et al. (2018), and Kim et al. (2019) that used DMEM + 2\% FBS, $\alpha M E M+2 \%$ horse serum, and DMEM + 5\% horse serum, respectively. DHA, docosahexaenoic acid; DMEM, Dulbecco's Modified Eagle Medium; EPA, eicosapentaenoic acid; FBS, fetal bovine serum; IL, Interleukin; mtDNA, mitochondrial DNA; Myf5, Myogenic factor 5; MyoD, myoblast determination protein 1; MyoG, myogenin; MDSCs, muscle-derived satellite cells; MRF, myogenic regulatory transcription factor; NM, not measured; nDNA, nuclear DNA; OCR, oxygen consumption rate; PAL, palmitate; Pgc-1 $\alpha$, peroxisome proliferatoractivated receptor-gamma co-activator 1-alpha; Pax, Paired box protein; TNF- $\alpha$, tumor necrosis factor; TFAM, mitochondrial transcription factor A; Tmem, transmembrane protein; $\downarrow$ downregulation; $\uparrow$ upregulation; $\leftrightarrow$ no change. All studies used DMEM and 2\% horse serum as myogenic differentiation media.

(Saini et al., 2017; Hsueh et al., 2018; Xu et al., 2018; LachamKaplan et al., 2020). In other studies, the cells were differentiated for 3-7 days and then treated with EPA or DHA for 16, 24, or $48 \mathrm{~h}$ before investigating myotube formation and expression of genes involved in myogenesis. The timing of exposure to fatty acids is an indicator of which processes are being investigated. 


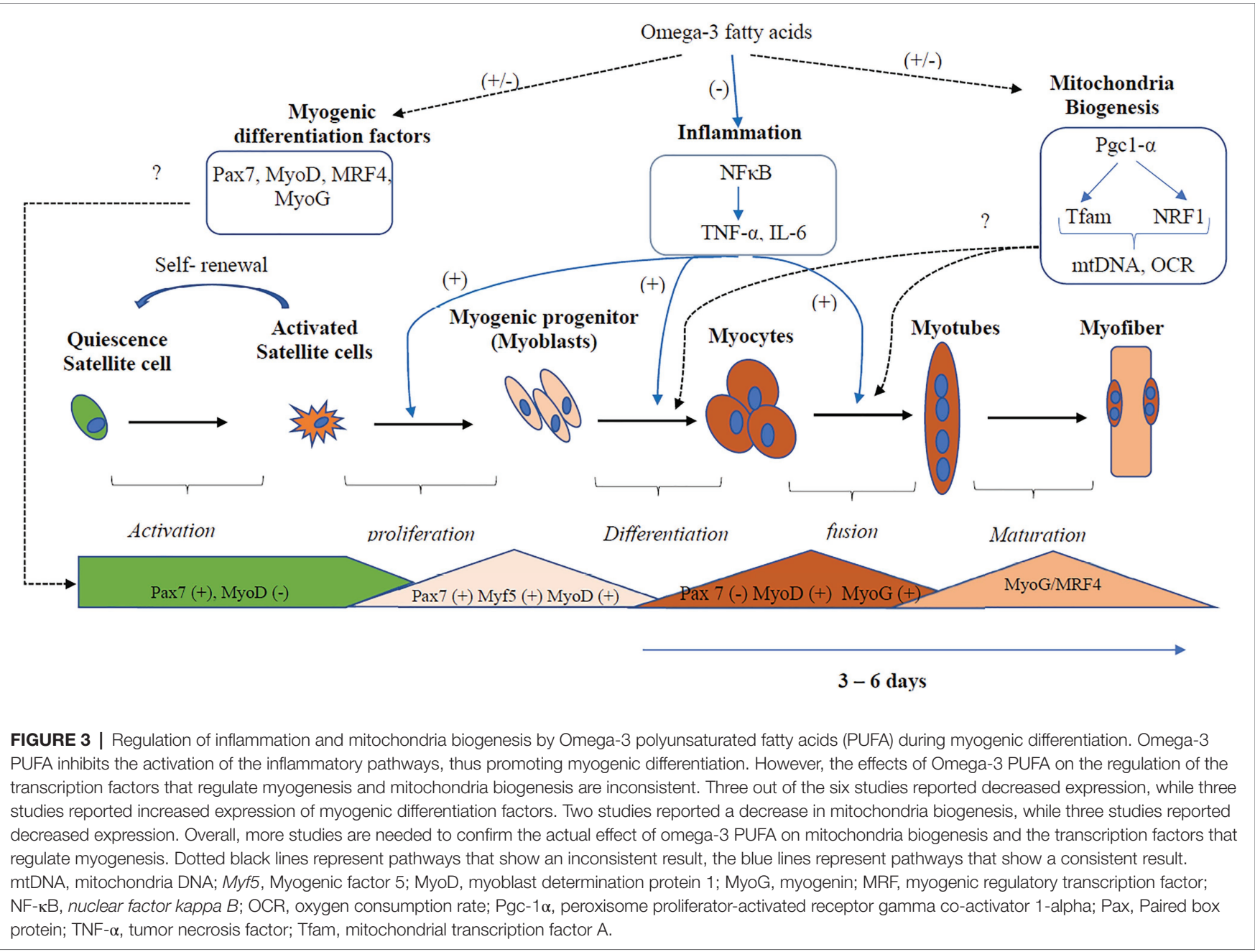

\section{Endogenous Omega-3 PUFA and Myogenesis in Cardiotoxin-Induced Muscle Injury}

Cardiotoxin is an agent used to induce injury in experimental models. Wang et al. (2021) recently examined the role of endogenous omega-3 PUFA on skeletal muscle repair and regeneration following cardiotoxin-induced injury (Wang et al., 2021). In this injury model, fat-1 mice, that endogenously produce omega-3 PUFA, had enhanced muscle repair and regeneration. The expression of Pax- $7^{+}$and MyoD, markers of myogenic differentiation were increased. This indicates a higher rate of satellite cell activation.

\section{EFFECTS OF OMEGA-3 PUFA ON MITOCHONDRIAL FUNCTION IN DIFFERENTIATING SKELETAL MUSCLE CELL}

Mitochondria biogenesis is regulated by the transcription factor peroxisome proliferator-activated receptor gamma co-activator
(Pgc-1 $\alpha$ ), which has the ability to co-activate and augment the expression of several other transcription factors (FernandezMarcos and Auwerx, 2011). The expression of nuclear respiratory factors 1 (Nrf1) and mitochondrial transcription factor A (Tfam) is increased by the activation of Pgc-1 $\alpha$ (Brown et al., 2010). Nrf1 subsequently upregulates Tfam to stimulate mitochondrial DNA (mtDNA) transcription and replication (Gleyzer et al., 2005). The function of the mitochondria can be assessed by measuring the oxygen consumption rate (OCR; Brand and Nicholls, 2011). Following injury, skeletal muscle-derived SCs increase their OCR and rates of glycolysis (Pala et al., 2018). Five out of eleven studies used $\mathrm{C} 2 \mathrm{C} 12$ cells, and one study used human myoblast to measure mitochondrial biogenesis.

\section{Effects of Omega-3 PUFA on Mitochondria Function in C2C12 Myoblast}

Compared to cells cultured in serum alone, mRNA expression of Tfam and Pgcl $\alpha$ was reduced in myoblasts cultured with EPA and DHA for 3 days (Hsueh et al., 2018). In addition, the ratio of mtDNA to nDNA and the OCR rate was lowered (Hsueh et al., 2018), suggesting fewer mitochondria and reduced mitochondrial biogenesis. Similarly, treatment with $50 \mu \mathrm{M}$ of 
EPA for $18 \mathrm{~h}$ decreased the OCR, basal respiration, proton leak, and ATP production (Kim et al., 2019). This reveals a negative correlation between high levels of EPA and DHA in the media and the expression of genes that regulate mitochondria biogenesis, suggesting inhibition of mitochondria function and biogenesis in differentiating myoblasts. On the contrary, an increase in the mRNA of Pgc1-a, Nrf1, and Tfam was observed when myotubes were treated with $50 \mu \mathrm{M} E P A+D H A$ for $24 \mathrm{~h}$, increased mtDNA/nDNA and mtDNA copy numbers were reported (Lee et al., 2016). These results suggest improvement of mitochondria biogenesis and function in the myogenic process with EPA+DHA treatment. While Young et al. (2021) reported increased mitochondrial respiration, another study reported no alteration of mitochondria respiration (determined by OCR) and function [UCQR2 (complex $\mathrm{V}$ and complex III)] by treatment of C2C12 myotubes with $50 \mu \mathrm{M}$ EPA and DHA for $24 \mathrm{~h}$ (Jeromson et al., 2018). The difference between these studies could potentially be attributed to the concentration and duration of the treatments, one of the studies treated with $50 \mu \mathrm{M}$ of the omega-3 PUFA for $24 \mathrm{~h}$ (Jeromson et al., 2018), and the other treated with $100 \mu \mathrm{M}$ for $48 \mathrm{~h}$ (Young et al., 2021).

\section{Effects of Omega-3 PUFA on Mitochondria Function in Human SCs}

The role of omega-3 PUFAs on mitochondrial biogenesis pathways in humans is not well-understood. Only one study published in the past 4 years isolated SCs from healthy individuals (Løvsletten et al., 2018). SCs were isolated from muscles of nine healthy donors and induced to differentiate to form multinucleated myotubes. Cells were provided $100 \mu \mathrm{M}$ EPA for $24 \mathrm{~h}$ increased the OCR, basal respiration, proton leak, and maximal respiration compared to palmitic acid. This suggests that the EPA improves mitochondrial function during the myogenic process. In support of this, Yoshino et al. (2016) explored the effect of omega-3 PUFAs (EPA and DHA) supplementation for 6 months on muscle transcriptome in older adults. Omega-3 PUFA supplementation to humans has been shown to upregulate the pathways involved in mitochondria function and extracellular matrix organization, a decrease in ubiquitin-mediated proteolysis, a decrease in pathways involved in the inhibition of mTOR (Yoshino et al., 2016). However, a minimal effect on the expression of individual genes involved in mitochondria was observed (Yoshino et al., 2016), which does not align with in vitro models, which show a decrease in OCR and basal respiration (Pinel et al., 2016; Hsueh et al., 2018; Kim et al., 2019). The difference could be attributed to the difference in the concentration used and duration of differentiation.

Overall, there were inconsistencies in the regulation of mitochondria function and biogenesis by EPA and DHA (Figure 3). The mitochondria function and biogenesis were determined by investigating the ratio of mitochondria DNA to nuclear DNA (mtDNA/nDNA), OCR, and the expression of genes involved in mitochondria biogenesis. One study reported no change (Jeromson et al., 2018), two studies reported an increase (Lee et al., 2016; Løvsletten et al., 2018), and three studies reported a decrease (Pinel et al., 2016; Hsueh et al., 2018; Kim et al., 2019) in mitochondrial function with $\mathrm{EPA}+\mathrm{DHA}$ treatment.
The inconsistencies in the experimental design make the study comparison challenging.

\section{EFFECTS OF OMEGA-3 FATTY ACIDS ON INFLAMMATION DURING MYOTUBE DIFFERENTIATION}

Only one study measured the effect of EPA and DHA on inflammation during myogenic differentiation (Chen et al., 2016). The transcription factor NF- $\kappa B$ is crucial for the induction of proinflammatory cytokine expression and plays an important role in the pathogenesis of diseases related to chronic inflammation (Martins et al., 2016; Liu et al., 2017). A high concentration of TNF- $\alpha$ plays a role in inducing proliferation of SCs and inhibition of myogenic differentiation through MyoD protein destabilization (Li, 2003; Langen et al., 2004). Inhibiting the action of TNF- $\alpha$ also inhibits the activity of p53 mitogen-activated protein kinases (MAPK), leading to the downregulation of expression of muscle differentiation markers such as MyoD and the transcription factor MyoG (Chen et al., 2007; Zhan et al., 2007). Palmitic acid-induced proinflammatory cytokine expression is associated with the development of insulin resistance in myotubes (Saghizadeh et al., 1996; Wellen and Hotamisligil, 2005). Co-treatment of C2C12 myotubes with $750 \mu \mathrm{M}$ palmitic acid and $50 \mu \mathrm{M}$ EPA and DHA for $16 \mathrm{~h}$ resulted in an inhibition of palmitic acid-induced proinflammatory cytokine expression (Chen et al., 2016). The expression of TNF- $\alpha$ and IL- 6 mRNA was reduced in the EPA and DHA treatment compared to the control. Similarly, EPA and DHA treatment abolished palmitic acid-induced NF- $\kappa \mathrm{B}$ activation by decreasing I $\mathrm{KB}-\alpha$ degradation, NF- $\kappa \mathrm{B}$ nuclear protein DNA binding activity, and NF- $\kappa \mathrm{B}$ transcriptional activity. EPA and DHA downregulates NF- $\kappa \mathrm{B}$ activation through several mechanisms, one of which is via a G-protein coupled receptor GPR120 (Talukdar et al., 2010). While ligand-stimulation of GPR120 led to an increase in glucose transport and translocation of glucose transporter (GLUT4) to the plasma membrane in adipocytes (Talukdar et al., 2010), and in muscle cells (Kim et al., 2015), their role in inflammation and myogenesis in skeletal muscle cells remains uncharacterised (McGlory et al., 2019). In adipocytes, DHA inhibits NF- $\kappa B$ activation and expression of NF- $\mathrm{BB}$ target genes and proteins via GPR120 (Talukdar et al., 2010). G-protein-coupled receptor kinase 2 (GRK2) phosphorylates the active form of G-protein-coupled receptor (Ribas et al., 2007) and plays a role in myogenesis (Garcia-Guerra et al., 2014); however, how this receptor is modulated by omega-3 PUFA is not known.

\section{LIMITATIONS AND FUTURE DIRECTION}

SCs play a crucial role in the repair of damaged skeletal muscle fiber in response to injury. An alternate approach to study similar conditions observed with muscle injury-induced inflammation is to monitor these cells during differentiation, 
coupled with a stimulus that recapitulates muscle injury (e.g., TNF- $\alpha$ or palmitate-induced inflammation). An appropriate control for these studies would be cells that are exposed to a similar amount of total fatty acids, without EPA and DHA, while the treatment group receives similar fatty acids plus EPA and DHA to maintain a similar molar concentration of total fatty acids in the media. Further, this could be further refined to ensure physiological concentrations. This would enable attribution of the effects specifically to EPA or DHA while enhancing the translatability of the findings. In vivo, muscle cells are exposed to a mixture of fatty acids. The only study that isolated SCs from human biopsy treated the skeletal muscle cells with $100 \mu \mathrm{M}$ of EPA (Løvsletten et al., 2018) which is twice the concentration (50 $\mu \mathrm{M}$ EPA or DHA) that were used in most of the studies that used $\mathrm{C} 2 \mathrm{C} 12$ cell. Correlating the concentrations used in the in vitro studies to physiological values is challenging; hence, it is difficult to extrapolate these results to humans. In addition, most studies did not report the level of incorporation of fatty acids during the differentiation. Future studies are needed to understand how the EPA and DHA modify myotube formation and myogenic differentiation. It is also essential to investigate the effects of omega-3 PUFA on SCs differentiation in cancer patients, to provide more insights on the regulation of skeletal muscle regeneration by EPA and DHA. Further studies should also explore the differentiation potential of SCs in response to stimuli that rehabilitate muscle injury and how exposure to EPA to DHA will alter the myogenic differentiation of the SCs. Future studies should focus on also examining whether omega-3 PUFA meditation of inflammation during satellite cell differentiation is via G-protein-coupled receptor. The physiological relevance of these in vitro studies remains unclear.

\section{REFERENCES}

Abdelmagid, S. A., Clarke, S. E., Nielsen, D. E., Badawi, A., El-Sohemy, A., Mutch, D. M., et al. (2015). Comprehensive profiling of plasma fatty acid concentrations in young healthy Canadian adults. PLoS One 10:e116195. doi: 10.1371/journal.pone.0116195

Abmayr, S. M., and Pavlath, G. K. (2012). Myoblast fusion: lessons from flies and mice. Development 139, 641-656. doi: 10.1242/dev.068353

Alami-Durante, H., Cluzeaud, M., Bazin, D., Mazurais, D., and Zambonino-Infante, J. L. (2011). Dietary cholecalciferol regulates the recruitment and growth of skeletal muscle fibers and the expressions of myogenic regulatory factors and the myosin heavy chain in European sea bass larvae. J. Nutr. 141, 2146-2151. doi: 10.3945/jn.111.146118

Almeida, C. F., Fernandes, S. A., Ribeiro Junior, A. F., Keith Okamoto, O., and Vainzof, M. (2016). Muscle satellite cells: exploring the basic biology to rule them. Stem Cells Int. 2016:1078686. doi: 10.1155/2016/1078686

Barthélémy, F., Defour, A., Lévy, N., Krahn, M., and Bartoli, M. (2018). Muscle cells fix breaches by orchestrating a membrane repair ballet. J. Neuromuscul. Dis. 5, 21-28. doi: 10.3233/JND-170251

Bhattacharya, D., and Scime, A. (2020). Mitochondrial function in muscle stem cell fates. Front. Cell Dev. Biol. 8:480. doi: 10.3389/fcell.2020.00480

Bhullar, A. S., Putman, C. T., and Mazurak, V. C. (2016). Potential role of omega-3 fatty acids on the myogenic program of satellite cells. Nutr. Metab. Insights 9, 1-10. doi: 10.4137/NMI.S27481

Braga, M., Simmons, Z., Norris, K. C., Ferrini, M. G., and Artaza, J. N. (2017). Vitamin D induces myogenic differentiation in skeletal muscle derived stem cells. Endocr. Connect. 6, 139-150. doi: 10.1530/EC-17-0008

\section{CONCLUSION}

In physiological conditions, there is a complex interaction between molecules in the regulation of pathways involved in myogenesis, hence the need for more studies to investigate this process. Most studies have reported beneficial effects of omega-3 PUFA in the skeletal muscle of cancer patients; however, the mechanism is not fully understood. Myogenic differentiation of satellite cells into myotube and further fusion into muscle fiber is one potential mechanism during skeletal muscle regeneration. There is a need for more studies to explore the effects of omega-3 PUFAs on human SCs myogenesis to get more insights on skeletal muscle regeneration during muscle injury and maintenance of skeletal muscle mass.

\section{AUTHOR CONTRIBUTIONS}

PI drafted the manuscript. VM edited and revised the manuscript. Both the authors contributed to the article and approved the submitted version.

\section{FUNDING}

This work was funded by Department of Agricultural, Food and Nutritional Science PhD Recruitment Fellowship and Canadian Institutes for Health Research RES0045289.

\section{ACKNOWLEDGMENTS}

We appreciate Md. Monirujjaman for proofreading the article.

Brand, M. D., and Nicholls, D. G. (2011). Assessing mitochondrial dysfunction in cells. Biochem. J. 435, 297-312. doi: 10.1042/BJ20110162

Brown, G. C., Murphy, M. P., Jornayvaz, F. R., and Shulman, G. I. (2010). Regulation of mitochondrial biogenesis. Essays Biochem. 47, 69-84. doi: 10.1042/bse0470069

Calder, P. C. (2010). Omega-3 fatty acids and inflammatory processes. Nutrients 2, 355-374. doi: 10.3390/nu2030355

Chapalamadugu, K. C., Robison, B. D., Drew, R. E., Powell, M. S., Hill, R. A., Amberg, J. J., et al. (2009). Dietary carbohydrate level affects transcription factor expression that regulates skeletal muscle myogenesis in rainbow trout. Comp. Biochem. Physiol. B: Biochem. Mol. Biol. 153, 66-72. doi: 10.1016/j.cbpb.2009.01.013

Chen, S. C., Chen, P. Y., Wu, Y. L., Chen, C. W., Chen, H. W., Lii, C. K., et al. (2016). Long-chain polyunsaturated fatty acids amend palmitate-induced inflammation and insulin resistance in mouse $\mathrm{C} 2 \mathrm{C} 12$ myotubes. Food Funct. 7, 270-278. doi: 10.1039/C5FO00704F

Chen, S. E., Jin, B., and Li, Y. P. (2007). TNF- $\alpha$ regulates myogenesis and muscle regeneration by activating p38 MAPK. Am. J. Physiol. Cell Physiol. 292, C1660-C1671. doi: 10.1152/ajpcell.00486.2006

Collins, C. A., Gnocchi, V. F., White, R. B., Boldrin, L., Perez-Ruiz, A., Relaix, F., et al. (2009). Integrated functions of Pax3 and Pax7 in the regulation of proliferation, cell size and myogenic differentiation. PLoS One 4:e4475. doi: 10.1371/journal.pone.0004475

Cornelison, D. D. (2008). Context matters: in vivo and in vitro influences on muscle satellite cell activity. J. Cell. Biochem. 105, 663-669. doi: 10.1002/jcb.21892

Dumont, N. A., Wang, Y. X., and Rudnicki, M. A. (2015). Intrinsic and extrinsic mechanisms regulating satellite cell function. Development 142, 1572-1581. doi: $10.1242 /$ dev.114223 
Fernandez-Marcos, P. J., and Auwerx, J. (2011). Regulation of PGC-1 $\alpha$, a nodal regulator of mitochondrial biogenesis. Am. J. Clin. Nutr. 93, 884S-890S. doi: 10.3945/ajcn.110.001917

Frontera, W. R., and Ochala, J. (2015). Skeletal muscle: a brief review of structure and function. Calcif. Tissue Int. 96, 183-195. doi: 10.1007/s00223-014-9915-y

Fukada, S. I. (2018). The roles of muscle stem cells in muscle injury, atrophy and hypertrophy. J. Biochem. 163, 353-358. doi: 10.1093/jb/mvy019

Gamage, D. G., Leikina, E., Quinn, M. E., Ratinov, A., Chernomordik, L. V., and Millay, D. P. (2017). Insights into the localization and function of myomaker during myoblast fusion. J. Biol. Chem. 292, 17272-17289. doi: 10.1074/jbc.M117.811372

Garcia-Guerra, L., Vila-Bedmar, R., Carrasco-Rando, M., Cruces-Sande, M., Martín, M., Ruiz-Gómez, A., et al. (2014). Skeletal muscle myogenesis is regulated by G protein-coupled receptor kinase 2. J. Mol. Cell Biol. 6, 299-311. doi: $10.1093 / \mathrm{jmcb} / \mathrm{mju} 025$

Gleyzer, N., Vercauteren, K., and Scarpulla, R. C. (2005). Control of mitochondrial transcription specificity factors (TFB1M and TFB2M) by nuclear respiratory factors (NRF-1 and NRF-2) and PGC-1 family coactivators. Mol. Cell. Biol. 25, 1354-1366. doi: 10.1128/MCB.25.4.1354-1366.2005

Hernández-Hernández, J. M., García-González, E. G., Brun, C. E., and Rudnicki, M. A. (2017). The myogenic regulatory factors, determinants of muscle development, cell identity and regeneration. Semin. Cell Dev. Biol. 72, 10-18. doi: 10.1016/j.semcdb.2017.11.010

Hsueh, T. Y., Baum, J. I., and Huang, Y. (2018). Effect of eicosapentaenoic acid and docosahexaenoic acid on myogenesis and mitochondrial biosynthesis during murine skeletal muscle cell differentiation. Front. Nutr. 5:15. doi: 10.3389/fnut.2018.00015

Jeromson, S., Mackenzie, I., Doherty, M. K., Whitfield, P. D., Bell, G., Dick, J., et al. (2018). Lipid remodeling and an altered membrane-associated proteome may drive the differential effects of EPA and DHA treatment on skeletal muscle glucose uptake and protein accretion. Am. J. Physiol. Endocrinol. Metab. 314, E605-E619. doi: 10.1152/ajpendo.00438.2015

Kassar-Duchossoy, L., Gayraud-Morel, B., Gomes, D., Rocancourt, D., Buckingham, M., Shinin, V., et al. (2004). Mrf4 determines skeletal muscle identity in Myf5:Myod double-mutant mice. Nature 431, 466-471. doi: 10.1038/nature02876

Katyare, S. S., and Mali, A. (2016). "Omega-3 fatty acids and mitochondrial functions," in Omega-3 Fatty Acids. eds. M. V. Hegde, A. A. Zanwar and S. P. Adekar (Switzerland: Springer International Publishing), 229-233.

Khor, S. C., Razak, A. M., Wan Ngah, W. Z., Mohd Yusof, Y. A., Abdul Karim, N., and Makpol, S. (2016). The tocotrienol-rich fraction is superior to tocopherol in promoting myogenic differentiation in the prevention of replicative senescence of myoblasts. PLoS One 11:e0149265. doi: 10.1371/journal. pone. 0149265

Kim, N., Kang, M. S., Nam, M., Kim, S. A., Hwang, G. S., and Kim, H. S. (2019). Eicosapentaenoic acid (EPA) modulates glucose metabolism by targeting AMP-activated protein kinase (AMPK) pathway. Int. J. Mol. Sci. 20:4751. doi: $10.3390 /$ ijms 20194751

Kim, N., Lee, J. O., Lee, H. J., Kim, H. I., Kim, J. K., Lee, Y. W., et al. (2015). Endogenous ligand for GPR120, docosahexaenoic acid, exerts benign metabolic effects on the skeletal muscles via AMP-activated protein kinase pathway. J. Biol. Chem. 290, 20438-20447. doi: 10.1074/jbc.M115.657379

Lacham-Kaplan, O., Camera, D. M., and Hawley, J. A. (2020). Divergent regulation of myotube formation and gene expression by E2 and EPA during in-vitro differentiation of C2C12 myoblasts. Int. J. Mol. Sci. 21:745. doi: 10.3390/ ijms 21030745

Lam, C. N., Isenring, E., de van der Schueren, M., and Van der Meij, B. S. (2020). The effect of oral omega-3 polyunsaturated fatty acid supplementation on muscle maintenance and quality of life in patients with cancer: a systematic review and meta-analysis. Clin. Nutr. ESPEN 40:667. doi: 10.1016/j. clnesp.2020.09.788

Langen, R. C., van der Velden, J. L., Schols, A. M., Kelders, M. C., Wouters, E. F., and Janssen-Heininger, Y. M. (2004). Tumor necrosis factor-alpha inhibits myogenic differentiation through MyoD protein destabilization. FASEB J. 18, 227-237. doi: 10.1096/f.03-0251 com

Latil, M., Rocheteau, P., Chatre, L., Sanulli, S., Memet, S., Ricchetti, M., et al. (2012). Skeletal muscle stem cells adopt a dormant cell state post mortem and retain regenerative capacity. Nat. Commun. 3:903. doi: 10.1038/ ncomms 1890
Lee, M.-S., Shin, Y., Moon, S., Kim, S., and Kim, Y. (2016). Effects of eicosapentaenoic acid and docosahexaenoic acid on mitochondrial DNA replication and PGC-1 $\alpha$ gene expression in C2C12 muscle cells. Prev. Nutr. Food Sci. 21:317. doi: 10.3746/pnf.2016.21.4.317

Lepper, C., Partridge, T. A., and Fan, C. M. (2011). An absolute requirement for Pax7-positive satellite cells in acute injury-induced skeletal muscle regeneration. Development 138, 3639-3646. doi: 10.1242/dev.067595

Li, Y.-P. (2003). TNF- $\alpha$ is a mitogen in skeletal muscle. Am. J. Physiol. Cell Physiol. 285, C370-C376. doi: 10.1152/ajpcell.00453.2002

Liu, T., Zhang, L., Joo, D., and Sun, S.-C. (2017). NF-kB signaling in inflammation. Signal Transduct. Target. Ther. 2:17023. doi: 10.1038/sigtrans.2017.23

Løvsletten, N. G., Bakke, S. S., Kase, E. T., Ouwens, D. M., Thoresen, G. H., and Rustan, A. C. (2018). Increased triacylglycerol-fatty acid substrate cycling in human skeletal muscle cells exposed to eicosapentaenoic acid. PLoS One 13:e208048. doi: 10.1371/journal.pone.0208048

Martins, G. R., Gelaleti, G. B., Moschetta, M. G., Maschio-Signorini, L. B. and de Campos Zuccari, D. A. P. (2016). Proinflammatory and antiinflammatory cytokines mediated by NF- $\mathrm{KB}$ factor as prognostic markers in mammary tumors. Mediat. Inflamm. 2016:9512743. doi: 10.1155/ 2016/9512743

McCarthy, J. J., Mula, J., Miyazaki, M., Erfani, R., Garrison, K., Farooqui, A. B., et al. (2011). Effective fiber hypertrophy in satellite cell-depleted skeletal muscle. Development 138, 3657-3666. doi: 10.1242/dev.068858

McGlory, C., Calder, P. C., and Nunes, E. A. (2019). The influence of omega-3 fatty acids on skeletal muscle protein turnover in health, disuse, and disease. Front. Nutr. 6:144. doi: 10.3389/fnut.2019.00144

McKenna, C. F., and Fry, C. S. (2017). Altered satellite cell dynamics accompany skeletal muscle atrophy during chronic illness, disuse, and aging. Curr. Opin. Clin. Nutr. Metab. Care 20, 447-452. doi: 10.1097/MCO.0000000000000409

Montarras, D., L'Honore, A., and Buckingham, M. (2013). Lying low but ready for action: the quiescent muscle satellite cell. FEBS J. 280, 4036-4050. doi: $10.1111 /$ febs. 12372

Morgan, J., and Partridge, T. (2020). Skeletal muscle in health and disease. Dis. Model. Mech. 13:dmm042192. doi: 10.1242/dmm.042192

Olguin, H. C., and Olwin, B. B. (2004). Pax-7 up-regulation inhibits myogenesis and cell cycle progression in satellite cells: a potential mechanism for selfrenewal. Dev. Biol. 275, 375-388. doi: 10.1016/j.ydbio.2004.08.015

Pala, F., Di Girolamo, D., Mella, S., Yennek, S., Chatre, L., Ricchetti, M., et al. (2018). Distinct metabolic states govern skeletal muscle stem cell fates during prenatal and postnatal myogenesis. J. Cell Sci. 131:jcs212977. doi: 10.1242/ jcs. 212977

Perandini, L. A., Chimin, P., Lutkemeyer, D. D., and Câmara, N. O. (2018). Chronic inflammation in skeletal muscle impairs satellite cells function during regeneration: can physical exercise restore the satellite cell niche? FEBS J. 285, 1973-1984. doi: 10.1111/febs. 14417

Peterson, J. M., Bakkar, N., and Guttridge, D. C. (2011). NF-кB signaling in skeletal muscle health and disease. Curr. Top. Dev. Biol. 96, 85-119. doi: 10.1016/B978-0-12-385940-2.00004-8

Pinel, A., Rigaudière, J.-P., Laillet, B., Pouyet, C., Malpuech-Brugère, C., Prip-Buus, C., et al. (2016). N- 3PUFA differentially modulate palmitateinduced lipotoxicity through alterations of its metabolism in C2C12 muscle cells. Biochim. Biophys. Acta 1861, 12-20. doi: 10.1016/j.bbalip.2015.10.003

Powell, D. J., McFarland, D. C., Cowieson, A. J., Muir, W. I., and Velleman, S. G. (2014). The effect of nutritional status on myogenic gene expression of satellite cells derived from different muscle types. Poult. Sci. 93, 2278-2288. doi: $10.3382 /$ ps.2013-03810

Price, P. T., Nelson, C. M., and Clarke, S. D. (2000). Omega-3 polyunsaturated fatty acid regulation of gene expression. Curr. Opin. Lipidol. 11, 3-7. doi: 10.1097/00041433-200002000-00002

Przewoźniak, M., Czaplicka, I., Czerwińska, A. M., Markowska-Zagrajek, A., Moraczewski, J., Stremińska, W., et al. (2013). Adhesion proteins-an impact on skeletal myoblast differentiation. PLoS One 8:e61760. doi: 10.1371/journal. pone. 0061760

Relaix, F., and Marcelle, C. (2009). Muscle stem cells. Curr. Opin. Cell Biol. 21, 748-753. doi: 10.1016/j.ceb.2009.10.002

Ribas, C., Penela, P., Murga, C., Salcedo, A., García-Hoz, C., Jurado-Pueyo, M., et al. (2007). The G protein-coupled receptor kinase (GRK) interactome: role of GRKs in GPCR regulation and signaling. Biochim. Biophys. Acta 1768, 913-922. doi: 10.1016/j.bbamem.2006.09.019 
Ryall, J. G., Dell'Orso, S., Derfoul, A., Juan, A., Zare, H., Feng, X., et al. (2015). The NAD+-dependent SIRT1 deacetylase translates a metabolic switch into regulatory epigenetics in skeletal muscle stem cells. Cell Stem Cell 16, 171-183. doi: 10.1016/j.stem.2014.12.004

Saghizadeh, M., Ong, J. M., Garvey, W. T., Henry, R. R., and Kern, P. A. (1996). The expression of TNF alpha by human muscle: relationship to insulin resistance. J. Clin. Invest. 97, 1111-1116. doi: 10.1172/JCI118504

Saini, A., Sharples, A. P., Al-Shanti, N., and Stewart, C. E. (2017). Omega-3 fatty acid EPA improves regenerative capacity of mouse skeletal muscle cells exposed to saturated fat and inflammation. Biogerontology 18, 109-129. doi: 10.1007/s10522-016-9667-3

Schiaffino, S., Dyar, K. A., Ciciliot, S., Blaauw, B., and Sandri, M. (2013). Mechanisms regulating skeletal muscle growth and atrophy. FEBS J. 280, 4294-4314. doi: 10.1111/febs. 12253

Seale, P., Sabourin, L. A., Girgis-Gabardo, A., Mansouri, A., Gruss, P., and Rudnicki, M. A. (2000). Pax7 is required for the specification of myogenic satellite cells. Cell 102, 777-786. doi: 10.1016/S0092-8674(00)00066-0

Serrano, A. L., Baeza-Raja, B., Perdiguero, E., Jardí, M., and Muñoz-Cánoves, P. (2008). Interleukin-6 is an essential regulator of satellite cell-mediated skeletal muscle hypertrophy. Cell Metab. 7, 33-44. doi: 10.1016/j.cmet.2007.11.011

Shin, S. K., Kim, J. H., Lee, J. H., Son, Y. H., Lee, M. W., Kim, H. J., et al. (2017). Docosahexaenoic acid-mediated protein aggregates may reduce proteasome activity and delay myotube degradation during muscle atrophy in vitro. Exp. Mol. Med. 49:e287. doi: 10.1038/emm.2016.133

Tachtsis, B., Camera, D., and Lacham-Kaplan, O. (2018). Potential roles of n-3 PUFAs during skeletal muscle growth and regeneration. Nutrients 10:309. doi: $10.3390 /$ nu10030309

Talukdar, S., Bae, E. J., Imamura, T., Morinaga, H., Fan, W., Li, P., et al. (2010). GPR120 is an omega-3 fatty acid receptor mediating potent antiinflammatory and insulin-sensitizing effects. Cell 142, 687-698. doi: 10.1016/j. cell.2010.07.041

Tidball, J. G. (2011). Mechanisms of muscle injury, repair, and regeneration. Compr. Physiol. 1, 2029-2062. doi: 10.1002/cphy.c100092

Wang, Z.-G., Zhu, Z.-Q., He, Z.-Y., Cheng, P., Liang, S., Chen, A.-M., et al. (2021). Endogenous conversion of $n-6$ to $n-3$ polyunsaturated fatty acids facilitates the repair of cardiotoxin-induced skeletal muscle injury in fat-1 mice. Aging (Albany NY) 13, 8454-8466. doi: 10.18632/aging.202655

Wellen, K. E., and Hotamisligil, G. S. (2005). Inflammation, stress, and diabetes. J. Clin. Invest. 115, 1111-1119. doi: 10.1172/JCI25102
Xu, J., Liu, D., Yin, H., Tong, H., Li, S., and Yan, Y. (2018). Fatty acids promote bovine skeletal muscle satellite cell differentiation by regulating ELOVL3 expression. Cell Tissue Res. 373, 499-508. doi: 10.1007/s00441-018-2812-3

Yamamoto, M., Legendre, N. P., Biswas, A. A., Lawton, A., Yamamoto, S., Tajbakhsh, S., et al. (2018). Loss of MyoD and Myf5 in skeletal muscle stem cells results in altered myogenic programming and failed regeneration. Stem Cell Rep. 10, 956-969. doi: 10.1016/j.stemcr.2018.01.027

Yang, W., and $\mathrm{Hu}$, P. (2018). Skeletal muscle regeneration is modulated by inflammation. J. Orthop. Translat. 13, 25-32. doi: 10.1016/j.jot.2018.01.002

Yin, H., Price, F., and Rudnicki, M. A. (2013). Satellite cells and the muscle stem cell niche. Physiol. Rev. 93, 23-67. doi: 10.1152/physrev.00043.2011

Yoshino, J., Smith, G. I., Kelly, S. C., Julliand, S., Reeds, D. N., and Mittendorfer, B. (2016). Effect of dietary n-3 PUFA supplementation on the muscle transcriptome in older adults. Physiol. Rep. 4:e12785. doi: 10.14814/phy2.12785

Young, K. G., Vanderboor, C. M., Regnault, T. R. H., and Guglielmo, C. G. (2021). Species-specific metabolic responses of songbird, shorebird, and murine cultured myotubes to n-3 polyunsaturated fatty acids. Am. J. Physiol. Regul. Integr. Comp. Physiol. 320, R362-R376. doi: 10.1152/ajpregu.00249.2020

Zammit, P. S. (2017). Function of the myogenic regulatory factors Myf5, MyoD, Myogenin and MRF4 in skeletal muscle, satellite cells and regenerative myogenesis. Semin. Cell Dev. Biol. 72, 19-32. doi: 10.1016/j.semcdb.2017.11.011

Zhan, M., Jin, B., Chen, S. E., Reecy, J. M., and Li, Y. P. (2007). TACE release of TNF- $\alpha$ mediates mechanotransduction-induced activation of p38 MAPK and myogenesis. J. Cell Sci. 120, 692-701. doi: 10.1242/jcs.03372

Zhang, J., Xu, X., Liu, Y., Zhang, L., Odle, J., Lin, X., et al. (2019). EPA and DHA inhibit myogenesis and downregulate the expression of muscle-related genes in C2C12 myoblasts. Gen. Dent. 10:64. doi: 10.3390/genes10010064

Conflict of Interest: The authors declare that the research was conducted in the absence of any commercial or financial relationships that could be construed as a potential conflict of interest.

Copyright (c) 2021 Isesele and Mazurak. This is an open-access article distributed under the terms of the Creative Commons Attribution License (CC BY). The use, distribution or reproduction in other forums is permitted, provided the original author(s) and the copyright owner(s) are credited and that the original publication in this journal is cited, in accordance with accepted academic practice. No use, distribution or reproduction is permitted which does not comply with these terms. 